LITERATURE REVIEW : PENGARUH PURSED LIPS BREATHING

TERHADAP SATURASI OKSIGEN PADA PASIEN PENYAKIT

PARU OBSTRUKSI KRONIK (PPOK)

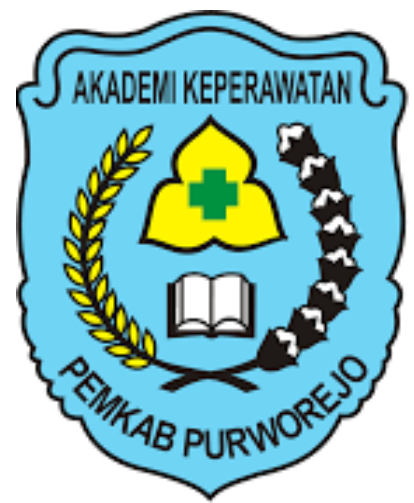

OLEH:

YUNI HARTATI

NIM.18094 


\section{NASKAH PUBLIKASI}

Diajukan Sebagai Salah Satu Syarat Mendapatkan Gelar Ahli Madya Keperawatan (A.Md.Kep)

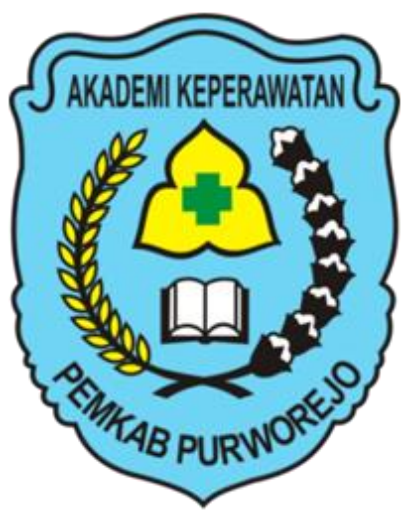

Oleh :

YUNI HARTATI

18094 


\section{LEMBAR PENGESAHAN}

Naskah Publikasi dengan judul "LITERATURE REVIEW : PENGARUH PURSED LIPS BREATHING TERHADAP SATURASI OKSIGEN PADA PASIEN PENYAKIT PARU OBSTRUKSI KRONIK (PPOK)" oleh Yuni Hartati (18094) telah diujikan di depan Dewan Penguji pada tanggal 25 Agustus 2021.

Dewan Penguji

Penguji I

Penguji II

Penguji III
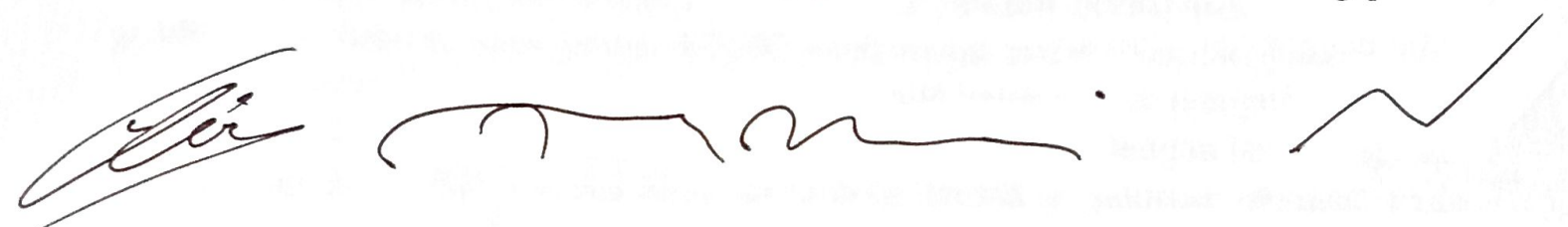

Wahexu Widodo, S.Kp.,Ns.,M.Kep.

NIDN.0609087301

Ahmad Muzaki,S.Kep.,Ns.,M.Kep. NIDN.0622038902

Wahidin, S.Kep.,Ns.,M.Kep.

NIDN.062203861

Mengetahui,

Akademi Keperawan Pemkab Purworejo

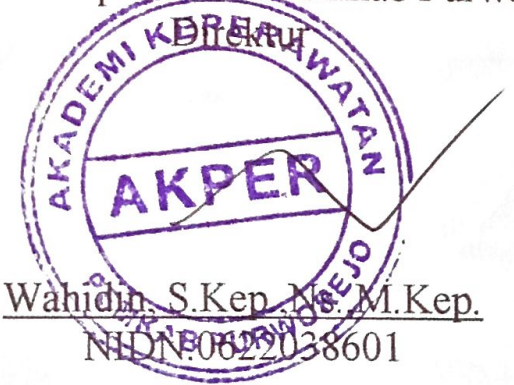




\title{
LITERATUR REVIEW : PENGARUH PURSED LIPS BREATHING TERHADAP SATURASI OKSIGEN PADA PASIEN PENYAKIT PARU OBSTRUKSI KRONIK (PPOK)
}

\author{
Yuni Hartati ${ }^{1}$, Wahidin ${ }^{2}$, Ahmad Muzaki $^{3}$ \\ Mahasiswa Akademi Keperawatan Pemkab Purworejo ${ }^{1}$ \\ Dosen Akademi Keperawatan Pemkab Purworejo ${ }^{2}$ \\ Dosen Akademi Keperawatan Pemkab Purworejo ${ }^{3}$ \\ Purworejo, (0275)3140576 \\ Email: yunihartati949@gmail.com
}

\begin{abstract}
ABSTRAK
Latar Belakang : Penyakit paru obstruksi kronik yaitu penyakit kronik yang ditandai adanya gangguan aliran udara didalam saluran pernapasan. Tanda dan gejala yang dialami oleh pasien PPOK yaitu sesak nafas. Teknik Pursed Lips Breathing merupakan intervensi non farmakologis yang untuk mengurangi sesak nafas, menguatkan otot-otot pernapasan sehingga berfungsi dengan baik. Tujuan: Mengetahui pengaruh Pursed Lips Breathing terhadap saturasi oksigen pada pasien penyakit paru obstruksi kronik. Metode: Jenis penelitian ini menggunakan metode literature review melalui google cendikia dan PUBMED dengan menggunakan kata kunci "Pursed Lips Breathing "+ saturasi oksigen + penyakit paru obstruksi kronik. Artikel jurnal yang dianalisis adalah yang dipunlikasikan sejak tahun 2016 sampai dengan 2020 yang diakses full text dalam format pdf. Hasil : Dari kelima jurnal yang dianalisis saturasi oksigen pada penderita penyakit paru obstruksi kronik mengalami peningkatan dengan menggunakan teknik pursed lips breathing. Kesimpulan: Teknik Pursed Lips Breathing (PLB) bermanfaat dalam meningkatkan saturasi oksigen pada pasien penyakit paru obstruksi kronik.
\end{abstract}

Kata kunci: Penyakit Paru Obstruksi Kronik, saturasi oksigen, Pursed Lips Breathing

\footnotetext{
ABSTRACT

Background : Chronic Obstructive Pulmonary Disease (COPD) is a chronic disease characterized by limited airflow in the respiratory tract. The main complaint experienced by COPD patients is shortness of breath. The pursed lips breathing technique is a non-pharmacological intervention that can help increase lung compliance to retrain breathing muscles to function properly. Objective : To determine the effect of pursed lips breathing on oxygen saturation in patients with Chronic Obstructive Pulmonary Disease (COPD). Methods : This type of
} 
research uses the literature review method through the google scholar and PUBMED using the keywords "Pursed Lips Breathing" + Oxygen Saturation + Chronic Obstructive Pulmonary Disease. The article articles analyzed are those published from 2016 to 2020 which are accessed in full text in pdf format. Results: From the five journals analyzed, oxygen saturation in patients with chronic obstructive pulmonary disease increased using the pursed lips breathing technique. Conclusion : The Pursed Lips Breathing (PLB) technique is effective in increasing oxygen saturation in patients with Chronic Obstructive Pulmonary Disease (COPD).

Keywords: Chronic Obstructive Pulmonary Disease, oxygen saturation, Pursed Lips Breathing

\section{Latar Belakang}

Penyakit Paru Obstruksi

Kronis (PPOK) adalah penyakit yang ditandai oleh hambatan aliran udara yang terus menerus dan bersifat progresif dan biasanya berhubungan dengan peningkatan respon inflamasi kronis terhadap partikel dan gas berbahaya pada saluran udara napas. (PDPI, 2003; dikutip dari artikel jurnal Amira, 2018).

Berdasarkan data dari Dinas Kesehatan pada tahun 2013 menunjukkan bahwa prevalensi PPOK di Indonesia sebesar 3,7 \%, dimana penyumbang terbesar untuk kasus PPOK adalah propinsi Nusa Tenggara Timur dengan prevalensi PPOK sebesar 10,0 \%. (Kemenkes RI, 2014; dikutip dari artikel Amira, 2018). Gambaran khas PPOK adalah adanya obstruksi saluran napas yang sangat bervariasi, mulai dari tanpa gejala, gejala ringan, hingga berat. Pasien dengan PPOK akan menunjukkan tanda dan gejala berupa batuk produktif dengan sputum purulen, bunyi napas wheezing, ronchi kasar ketika inspirasi dan ekspirasi (McPhee, 2010 dikutip dari artikel jurnal Venia, 2010). Pasien dengan PPOK juga akan menunjukkan gejala penurunan berat badan, penurunan compliance paru, dan obstruksi jalan napas saat fungsi paru memburuk maka risiko terjadinya hipoksia juga akan meningkat. Kejadian hipoksemia pada pasien PPOK menyebabkan penurunan kualitas hidup, berkurangnya toleransi terhadap latihan, mengurangi fungsi otot rangka, dan 
akhirnya meningkatkan risiko kematian. Selanjutnya diketahui bahwa sebagian besar pasien PPOK mengalami hipoksemia dan penurunan saturasi oksigen darah arteri (Sinambela, 2015; dikutip dari artikel junral venia, 2020).

Adapun salah satu teknik non farmakologis yang dapat diberikan dan diajarkan pada penderita PPOK adalah dengan melatih otot pernapasan khususnya otot paru supaya tidak lemah dan dapat memperkuat otot diafragma. Pursed Lips Breathing adalah cara yang mudah dilakukan untuk meIatih otot diafragma (Ambrosino dan Serradori, 2011 ; dikutip dari artikel jurnal Venia, 2020).

\section{Metode Penelitian}

Metode penelitian ini menggunakan Iiteratur review, yaitu mencari artikel dan menganalisis artikeI-artikeI penelitian mengenai tentang pursed Iips breathing. Pencarian artikel diIakukan menggunakan pendekatan data seperti Google Cendekia menggunakan kata kunci "Pursed Iips breathing", "Pursed Lips Bretahing" + saturasi oksigen, "Pursed Iips breathing" + saturasi oksigen + PPOK, "Pursed Iips breathing + oxygen saturation + COPD". dan menggunakan situs web pencari artikel jurnal internasional seperti PUBMED dengan menggunakan kata kunci berbahasa Inggris yaitu Pursed Lips Breathing oxygen saturation COPD. ArtikeI dipilih adaIah artikeI yang dipublikasikan antara tahun 2016 sampai dengan tahun 2020 yang bisa dibuka fulltext daIam format pdf .

Analisa data dilakukan dengan cara mendiskusikan dan meringkas literatur kemudian membandingkan beberapa literatur dan selanjutnya dituangkan dalam pembahasan. Dalam mereview sebuah literatur bisa melakukannya dengan beberapa cara, diantaranya: Mencari kesamaan (Simmiliarity), mencari ketidaksamaan (Contrast), memberikan pandangan (Criticze), membandingkan (Compare) dan meringkas (Summarize). 


\section{Hasil}

Hasil analisis literatur review ini disajikan dalam Tabel 1.

Tabel 1. Hasil Rekapitulasi Artikel Literatur Review

\begin{tabular}{|c|c|c|c|c|c|}
\hline$\overline{\mathrm{No}}$ & $\begin{array}{c}\text { Nama } \\
\text { Penulis }\end{array}$ & Judul Artikel & $\begin{array}{c}\text { Metode } \\
\text { Penelitian }\end{array}$ & $\begin{array}{c}\text { Subjek } \\
\text { Penelitian }\end{array}$ & Hasil \\
\hline 1. & $\begin{array}{l}\text { Budiono,dkk, } \\
\text { (2017) }\end{array}$ & $\begin{array}{l}\text { The Effect Of Pursed } \\
\text { Lips Breathing In } \\
\text { Increasing Oxygen } \\
\text { Saturation In Patients } \\
\text { With Chronic } \\
\text { Obstructive } \\
\text { Pulmonary Disease } \\
\text { In Internal Ward } 2 \text { Of } \\
\text { The General Hospital } \\
\text { Of Dr. R. } \\
\text { Soedarsono Pasuruan. }\end{array}$ & $\begin{array}{l}\text { a pre - } \\
\text { exprimental } \\
\text { desgn with pre- } \\
\text { post test design. }\end{array}$ & $\begin{array}{l}24 \text { responden } \\
\text { with COPD, } \\
\text { selected using } \\
\text { simple random } \\
\text { sampling } \\
\text { technique. }\end{array}$ & $\begin{array}{lr}\text { difference } & \text { in } \\
\text { oxygen } & \\
\text { saturation } & \\
\text { before and } & \text { after } \\
\text { pursed } & \text { lips } \\
\text { breathing } & \text { in } \\
\text { patients } & \text { with } \\
\text { COPD. } & \end{array}$ \\
\hline 2. & $\begin{array}{ll}\text { Amira } & \\
\text { Permata Sari } \\
\text { Tarigan dan } \\
\text { Juliandi } & \\
(2018) & \end{array}$ & $\begin{array}{lr}\text { Pernafasan } & \text { Pursed } \\
\text { Lip } & \text { Breathing } \\
\text { Meningkatkan } & \\
\text { Saturasi } \quad \text { Oksigen } \\
\text { Penderita Penyakit } \\
\text { Paru Obtruktif Kronis } \\
\text { PPOK Derajat II. }\end{array}$ & $\begin{array}{l}\text { penelitian ini } \\
\text { menggunakan } \\
\text { pre- } \\
\text { eksperimentald } \\
\text { esign, dengan } \\
\text { rancangan one } \\
\text { group pre tes - } \\
\text { post tes design. }\end{array}$ & $\begin{array}{l}\text { Menggunakan } \\
\text { total sampling } \\
\text { jumlah sampel } \\
\text { adalah } \\
\text { sebanyak } 36 \\
\text { orang pasien } \\
\text { penderita } \\
\text { PPOK drajat II } \\
\text { Poli PPOK } \\
\text { Rumah Sakit } \\
\text { Umum Pusat } \\
\text { Haji Adam } \\
\text { Malik Medan. }\end{array}$ & $\begin{array}{l}\text { terdapat } \\
\text { manfaat pursed } \\
\text { Iips breathing } \\
\text { untuk } \\
\text { meningkatkan } \\
\text { saturasi oksigen } \\
\text { pada PPOK } \\
\text { dengan nilai } \mathrm{p}= \\
0,001 \text {. }\end{array}$ \\
\hline 3. & $\begin{array}{l}\text { Shahriar } \\
\text { Sakhaei, } \\
\text { dkk } \\
(2018)\end{array}$ & $\begin{array}{l}\text { The impact of Pursed } \\
\text { Lip Breathing } \\
\text { Manuever on } \\
\text { Cardiac, Respiratory } \\
\text { and Oxygenation } \\
\text { Parameters in COPD } \\
\text { Patients. }\end{array}$ & $\begin{array}{l}\text { was a three- } \\
\text { group clinicaI } \\
\text { triaI, } \\
\text { purposefully } \\
\text { conducted with } \\
\text { the } \\
\text { participation of } \\
\text { patients with } \\
\text { COPD unit of } \\
\text { Madani } \\
\text { hospitaI Khoy, } \\
\text { in 2017. }\end{array}$ & $\begin{array}{l}60 \text { subjects of } \\
\text { patients with } \\
\text { COPD and } \\
\text { heaIthy } \\
\text { individual } \\
\text { referring to the } \\
\text { spirometric } \\
\text { unit in Madani } \\
\text { hospitaI Khoy, } \\
\text { in } 2017 \text {. }\end{array}$ & $\begin{array}{l}\text { On evaluation } \\
\text { within } \\
\text { intervention of } \\
\text { Saturation on } \\
\text { Peripheral } \\
\text { Oxygen index } \\
\text { increased to } \\
2,05 \% \\
\text { brfore, form } \\
\end{array}$ \\
\hline
\end{tabular}




\begin{tabular}{|c|c|c|c|c|c|}
\hline 4. & $\begin{array}{l}\text { Hilma } \\
\text { Wahidati, dkk } \\
\text { (2019) }\end{array}$ & $\begin{array}{l}\text { The Effectiviness of } \\
\text { Tripod Position And } \\
\text { Pursed Lips } \\
\text { Breathing to Enche } \\
\text { Oxygen Saturation in } \\
\text { Patients With COPD }\end{array}$ & $\begin{array}{l}\text { meperngunakan } \\
\text { metode quasi } \\
\text { eksperimentaI } \\
\text { menggunakan } \\
\text { pendekatan } \\
\text { pretest-post tes } \\
\text { design. }\end{array}$ & $\begin{array}{l}\text { teknik } \\
\text { pengambilan } \\
\text { sampeI } \\
\text { menggunakan } \\
\text { total sampIing } \\
\text { dengan non- } \\
\text { probabiIity } \\
\text { sampling dan } \\
\text { besar sampel } \\
34 \text { pasien di } \\
\text { willayah kerja } \\
\text { Puskesmas. }\end{array}$ & $\begin{array}{l}\text { Ada pengaruh } \\
\text { antara tripod } \\
\text { position dan } \\
\text { pursed Iips } \\
\text { breathing } \\
\text { terhadap } \\
\text { peningkatan } \\
\text { saturasi oksigen } \\
\text { pada penderita } \\
\text { PPOK. }\end{array}$ \\
\hline 5. & $\begin{array}{l}\text { Venia Evika } \\
\text { Al Islami dan } \\
\text { Suyanto } \\
(2020)\end{array}$ & $\begin{array}{lr}\text { Perbedaan } & \text { Nilai } \\
\text { Saturasi } & \text { Okisgen } \\
\text { Pasien } & \text { PPOK } \\
\text { Menggunakan Pursed } \\
\text { Lip Breathing dan } 6 \\
\text { Minuts Walk Exercise }\end{array}$ & $\begin{array}{l}\text { Jenis } \\
\text { metodenya } \\
\text { adalah kuasi } \\
\text { eksperimen } \\
\text { dengan } \\
\text { pendekatan two } \\
\text { group pre and } \\
\text { posttes design. }\end{array}$ & $\begin{array}{l}\text { Pasien PPOK } \\
\text { menjdi } \\
\text { populasi } \\
\text { penelitian yang } \\
\text { diambil } \\
\text { sampelnya } \\
\text { dengan teknik } \\
\text { purposive } \\
\text { sampling } \\
\text { sebanyak } 60 \\
\text { dibangsal } \\
\text { rawat inap dan } \\
\text { rawat jaIan } \\
\text { dengan } \\
\text { golongan } \\
\text { PPOK drajat } \\
\text { ringan di BaIai } \\
\text { Kesehatan } \\
\text { Paru } \\
\text { Masyarakat } \\
\text { Surakarta. }\end{array}$ & $\begin{array}{l}\text { Ada pengaruh } \\
\text { teknik pursed } \\
\text { lips breathing } \\
\text { untuk } \\
\text { meningkatkan } \\
\text { saturasi oksigen } \\
\text { lebih efektif } \\
\text { dibandingkan } \\
\text { dengan teknik } 6 \\
\text { Minuts Walk } \\
\text { Exercise }\end{array}$ \\
\hline
\end{tabular}

\section{Pembahasan}

Penurunan saturasi oksigen yang terjadi pada pasien PPOK terjadi pada saat serangan sesak nafas yang dialami. Sehingga jumlah oksigen dalam sel darah merah yang dibawa hemoglobin menuju jantung kiri dan dialirkan menuju kapiler perifer sedikit, gangguan suplai oksigen dalam darah pada arteri akan meyebabkan penurunan nilai saturasi oksigen yang akan berdampak buruk bagi tubuh penderita (Muttaqin, 2008 ; dikutip dari artikel jurnal Hilma, dkk 2019).

Dalam artikel Hilma (2019) Saturasi oksigen pada penderita PPOK sebelum dilakukan tindakan menunjukkan nilai saturasi oksigen kurang dari nilai normal yaitu $\leq 95 \%$ hingga $92 \%$. Saturasi oksigen bagi 
penderita PPOK akan mengalami penurunan hingga $<85 \%$, hal ini terjadi karena adanya sumbatan jalan napas, penurunan fungsi otot diafragma dan udara yang terjebak dalam paru, sehingga pertukaran udara dalam paru tidak terjadi.

Pursed Lip Breathing (PLB) merupakan salah satu teknik latihan pernafasan yang melibatkan pernafasan melalui perlawanan yang diciptakan dengan penyempitan bibir. Efek dari PLB adalah meningkatkan volume tidal dan volume akhir ekspirasi paru dan dampaknya adalah meningkatkam kapasitas otot-otot pernafasan untuk memenuhi kebutuhan dalam memberikan tekanan pernafasan (Ambrosino dan Serradori, 2006; dikutip dalam artikel jurnal Amira, 2020). Penelitian yang dilakukan oleh Budiono,dkk, (2017) pada pasien PPOK di RS Dr. R Soedarsono Pasuruan menunjukan adanya pengaruh teknik pursed lips breathing untuk meningkatkan saturasi oksigen pada penderita PPOK.

Hasil yang sama juga diperoleh dalam penelitian yang dilakukan oleh
Amira Permata Sari Taringan dan Julianti (2018) yang melakukan teknik pursed lips breathing di RSUP Hasi Adam Malik dengan hasil ada peningkatan saturasi oksigen pada penderita PPOK. Pada tahun yang sama juga dilakukan penelitian oleh Shariar Sakhaei, dkk, (2018) bahwa tehnik pursed lips breathing mampu menaikan saturasi oksigen, menurunkan frekuensi pernapasan pada pasien PPOK di RS Madani Khoy.

Penelitian dari Hilma Wahidati, dkk (2019) yang memberikan teknik pursed lips breathing dan teknik tripod position sama-sama mampu menaikan saturasi oksigen pada pasien PPOK, namun teknik pursed lips breathing lebih efisien dan lebih dapat menaikan saturasi oksigen dibandingkan dengan teknik tripod position. Penelitian yang lain dilakukan oleh Venia Evika $\mathrm{Al}$ Islami dan Suyanto (2020) memberikan teknik pursed lips breathing dan 6 minutes walk kepada pasien PPOK derajat ringan di Balai Kesehatan Paru Masyarakat Surakarta, namun teknik 6 minutes walk kurang memberikan hasil yang signifikan, pada teknik pursed lips breathing lebih efektif dalam 
meningkatkan saturasi oksigen pada pasien PPOK.

Dari kelima jurnal yang digunakan ada 2 Metode peneltitian yang sama dilakukan oleh Budiono, dkk (2017) dan Amira, dkk (2018), keduanya sama-sama menggunakan metode pre-experimental menggunakan pendekatan pre-potest design. Sugiono (2014) berpendapat bila metode pre-experimentaI adalah sebuah rancangan yang meliputi sekeIompok yang diberikan sebelum dan sesudah diujikan. Metode penelitian yang sama selanjutnya dilakukan pada penelitan Hilma, dkk (2019) dan Venia E \& Suyanto (2020), keduanya sama-sama menggunakan quasi-experimental pretest post-test design. Sugiyono (2014) berpendapat quasi-experimentaI terdapat keIompok kontroI, namun tidak bisa bergerak seluruhnya sebagai kontroI variabeI terikat yang mempengaruhi jalannya penelitian. Penelitian yang dilakukan Shahrir ,dkk (2018) menggunakan metode three group clinicil trial study dengan pendekatan experimental and controI. Menurut Sugiyono (2014) uji klinis merupakan peneitial eksperimentaI yang terprogram dilaukan pada responden, diberikan intervensi pada responden lalu intervensi tersebut akan dianalisis.

Pendekatan yang sama dilakukan pada penelitian Budiono (2017), dan Hilma, dkk (2019) menggunakan pendekatan pre-posttest design yaitu memberikan tes awal sebleum diberikan perlakauan dan tes akhir sesudah perlakuan, pada penelitian yang dilaukan oleh Amira, dkk (2018) menggunakan pendekatan one group pre-test post-test design iaIah melakukan tes awaI sebeum diberikan perlakauan dan test akhir sesudah perlakuan disatu keIompok, selanjutnya pada penelitian oleh Shahrir, dkk (2018) menggunakan pendekatan three-group clinical trial randomised controlled yaitu kelompok dipilih secara acak kemudian diberikan test awaI sebelum dilakukan intervensi dan test akhir sesudah dilakukan intervensi pada kelompok terkontrol. Sedangkan, pendekatan yang dilakukan pada penelitian Venia E \& Suyanto (2020) menggunakan pendekatan two group pre-test post-test design, yang artinya rancangan penelitian yang dilakukan kedua kelompok berbeda 
untuk diberikan intervensi yang beda dan dicek sebelum dilakukan intervensi dan sesudah dilakukan intervensi.

Tehnik pengambilan sampel yang sama dilakukan pada penelitian Amira, dkk (2018), Hilma, dkk (2019) dan yaitu dengan enggunakan totaI sampling, Sugiyono (2014) berpendapat jika totaI sampling iaIah teknik memilug sampel dimana seluruh orang didalam populasi dipakai untuk sampeI, penelitian selanjutnya dilaukan Budiono (2017), dan Shahrir, dkk (2018) menggunakan tehnik pengambilan sampel acak atau random sampling, Sugiyono (2017) berpendapat pengambilan sampeI dari popuIasi diIakukan dengan cara acak tanpa ada ketentuan tertentu, sedangkan penelitian oleh Venia E \& Suyanto (2020) menggunakan teknik pengambilan sampel purposive sampling yaitu seperti yang dikemukakan oleh Sugiyono (2016) bahwa teknik untuk mengambiI sampeI dengan mempertimbangkan sesuai dengan yang diinginkan peneliti.

Jumlah sampel yang sama digunakan pada penelitian Shahrir, dkk (2018) dan penelitian Venia E \& Suyanto (2020) ,keduanya sama menggunakan jumlah sampel sebanyak 60 responden. Menurut Sugiyono (2019) mengemukakan bahwa ukuran sepel yang layak dalam penelitian yang baik pada penelitian berkisar dari 30 sampai dengan 500 responden. Budiono (2017), menggunakan sampel sebanyak 24 responden. Amira, dkk (2018) menggunakan 36 responden,dan penelitian Hilma, dkk (2019) menggunkan 34 responden. Pada penelitian ini menggunakan ukuran sampel yang sudah sama dengan ketentuan yang dikemukakan oleh Mahmud pada tahun 2011, mengatakan bahwa besar kisaran terkecil sampel pada metode eksperial yaitu 15 responden per kelompok.

Pandangan penulis berdasarkan penelitian dari 5 jurnal diatas sependapat bahwa tehnik pursed lips bretahing dapat menaikan saturasi oksigen dimana tehnik ini mudah dilakukan oleh siapapun khususnya pada pasien penderita penyakit paru obstruksi kronik. Teknik ini jika dilakukan secara berulang dan teratur akan memberikan manfaat seperti menguatkan otot paru, menurunkan frekuensi oksigen dan meningkatkan saturasi oksigen. 
Dari beberapa literature di atas menunjukkan ada pengaruh pursed lips bretahingterhadap saturasi oksigen pada pasien PPOK. Tehnik pursed lips bretahing dapat digunakan sebagai terapi nonfarmakologis untuk menaikan saturasi oksigen pada pasien penyakit paru obstruksi kronik.

\section{Kesimpulan}

Berdasarkan uraian diatas dari 5 jurnal yang telah dilakukan review maka menunjukkan bahwa tehnik pursed lips bretahing dapat digunakan sebagai terapi non farmakologis untuk meningkatkan saturasi oksigen. Hasil dari 5 jurnal diatas juga menunjukkan bahwa ada pengaruh teknik pursed lips bretahing terhadap saturasi oksigen pada pasien penyakit paru obstruksi kronik. Pursed Iips breathing yaitu teknik latihan otot pernapasan dengan menngunakan gabungan 2 siklus yaitu tarik napas atau inspirasi dengan melalui hidung dengan lalu membuang napas atau ekspirasi dengan mengerucutkan bibir selama kurang lebih 2 sampai 5 menit ( Hudak dan Gallo, 2011). Bila dilakukan secara rutin dan benar dapat menguatkan otot paru, menurunkan frekuensi pernapasan dan meningkatkan saturasi oksigen.

\section{Ucapan Terimakasih}

Penulis mengucapkan terima kasih kepada Direktur Akper Pemkab Purworejo dan dosen pembimbing yang telah memberikan bimbingan dan dukungan dalam penyelesaian publikasi ini.

\section{Daftar Pustaka}

Ambrosino, N. Serradori, M. (2011). Comprehensive Treatment Of Dyspnea In Chronic Obstructive Pulmonary Disease Patient. University Hospital of Pisa: Long Termhealth Care.

Budiono, dkk. (2017). The Effect Of Pursed Lips Breathing In Increasing Oxygen Saturation In Patients With Chronic Obstructive Pulmonary Disease In Internal Ward 2 Of The General Hospital Of Dr. $\quad R$. Soedarsono Pasuruan.Vol. 3. Diakses pada 20 September 2020 pukul 15:20 WIB.

Hudak, C.M., dan Gallo, Barbara, M. (2011). Keperawatan Kritis (edisi 8). Jakarta: Buku Kedokteran EGC.

Islami, VEA dan Suyanto. (2020). Perbedaan Nilai Saturasi Oksigen Pasien PPOK Menggunakan Pursed Lip Breathing Dan 6 Minutes Walk Exercise Vol.4. Diakses 
19 Januari 2021 pukul 12:00 WIB.

Kemenkes RI, 2014, Riset Kesehatan Dasar tahun 2013. http://www.depkes.go.id/reso urces/download/general/Hasi 1\%20Riskesdas\%202013.pdf.

Diakses tanggal 20 Januari 2021.

McPhee, S. J. \& Ganong, W. F. (2010). Patofisiologi Penyakit: Pengantar Menuju Kedokteran Klinis, Edisi 5. Jakarta: EGC.

Muttaqin, A. (2008). Asuhan keperawatan Klien dengan Gangguan Sistem Pernapasan. Jakarta: Salemba medika.

Perhimpunan Dokter Paru Indonesia, (2003). PPOK ; Pedoman, diagnosis dan penatalaksanaan di Indonesia. http://www.klikpdpi.com/kons ensus/konsensusppok/ppok.pdf, diakses tanggal 21 Januari 2016.

Shahriar Sakhaei, dkk. (2018).

The Impact of Pursed-lips Breathing Maneuver on Cardiac, Respiratory, and Oxygenation Parameters in COPD Patients. Vol.6. Diakses 20 Januari 2021 pukul 09:15 WIB.

Sinambela, A. H., dkk. (2015). Pengaruh Latihan Fisik Terhadap Saturasi Oksigen pada Penderita Penyakit
Paru Obstruktif Kronik

Stabil. J Respir

Indo.Vol.35(3).

Sugiyono. (2008). Metode Penelitian uantitatif Kualitatif dan $R \& D$. Bandung:

ALFABETA.

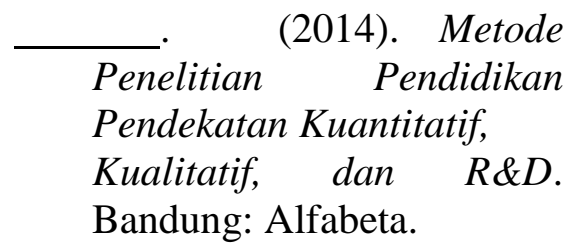
(2016). Metode Penelitian Kuantitatif, Kualitatif dan $R \& D$. Bandung: PT Alfabet.

Penelitian (2017). Metode
Kualitatif, dan $R \& D$.
Bandung: Alfabeta, CV.
. (2019). Statistika untuk Penelitian. Bandung : CV Alfabeta.

Taringan, APS. (2018). Pernafasan Pursed Lip Breathing Meningkatkan Saturasi Oksigen Penderita Penyakit Paru Obstruktif Kronis (Ppok) Derajat II. Vol 1. Diakses pada 17 Desember 2020 pukul 12:15 WIB.

Wahidati Hilma, dkk. (2019) . The Effectiveness Of Tripod Position And Pursed Lips Breathing To Enhance Oxygen Saturation In Patients With COPD. Vol.3. Diakses pada 20 Januari 2021 pukul 20:15 WIB. 